\title{
ANALISA SISTEM JARINGAN DRAINASE (STUDI KASUS : DESA SUMENGKO, KECAMATAN SUKOMORO, KABUPATEN NGANJUK)
}

\author{
Nita Kusuma Agustin*1, Ahmad Ridwan ${ }^{2}$, Sudjati ${ }^{3}$. \\ ${ }^{1,2,3}$ Fakultas Teknik, Universitas Kadiri. \\ e-mail:*1kusumanita18@gmail.com, 2ahmad ridwan@unik-kediri.ac.id, \\ ${ }^{3}$ sudjati@unik-kediri.ac.id.
}

\begin{abstract}
Drainage channels or flood control buildings are 12 general components of physical infrastructure that are useful to meet the needs of the community and are an important component of road support buildings. In the problem of flooding that occurred in some neighborhoods in the village of Sumengko, an analysis of the existing drainage channels is needed. This activity is expected to help solve flood problems in the area. The research method used is descriptive quantitative, the method of calculation, and translation of the results of field data processing. With this method, the research results obtained at $0.41 \mathrm{~m} 3 /$ second for flood planning $(Q r)$ using a rational formula for a 10-year period and $0.12 \mathrm{~m} 3 /$ second for the capacity of the drainage channel $(Q s)$. While the comparative requirements that meet are $Q s \geq Q r$. So there needs to be an analysis of the drainage channel. From the analysis of the dimensions of the drainage channel, a new trapezoidal channel with a width of the bottom channel (b): $0.40 \mathrm{~m}$; depth of waterlogged channel (h): 0.35 $m$; and guard height (w): $0.20 \mathrm{~m}$.
\end{abstract}

Keywords: $\quad$ Drainage Channels, Discharge Plans, Channel Capacity, Flood

\begin{abstract}
Abstrak
Saluran drainase atau bangunan pengendali banjir merupakan 12 komponen umum fasilitas fisik insfrastruktur yang berguna untuk memenuhi kebutuhan masyarakat dan merupakan kompenen penting bangunan penunjang jalan. Dalam permasalahan banjir yang terjadi pada sebagian lingkungan Desa Sumengko diperlukan analisa terhadap saluran drainase eksisting. Kegiatan ini diharapkan dapat membantu menyelesaikan permasalahan banjir di daerah tersebut. Metode penelitian yang digunakan deskriptif kuantitatif, yaitu metode perhitungan dan penjabaran dari hasil pengolahan data lapangan. Dengan metode tersebut didapatkan hasil penelitian sebesar $0,41 \mathrm{~m}^{3} /$ detik untuk debit banjir rencana (Qr) yang menggunakan rumus rasional untuk periode 10 tahunan dan $0,12 \mathrm{~m}^{3} /$ detik untuk untuk kapasitas daya tampung saluran drainase (Qs). Sedangkan Syarat perbandingan yang memenuhi ialah Qs $\geq$ Qr. Sehingga perlu adanya analisa terhadap saluran drainase tersebut.Dari analisa dimensi saluran drainase yang dilakukan, menghasilkan saluran baru bentuk trapesium dengan lebar bawah saluran (b) : 0,40 m; kedalaman saluran yang tergenang air $(\mathrm{h}): 0,35 \mathrm{~m}$; dan tinggi jagaan $(\mathrm{w}): 0,20 \mathrm{~m}$.
\end{abstract}

Kata Kunci : $\quad$ Saluran Drainase, Debit Rencana, Kapasitas Saluran, Banjir 


\section{PENDAHULUAN}

Pada umumnya banjir disebabkan oleh curah hujan yang tinggi di atas normal, sehingga sistem pengaliran air yang terdiri dari sungai dan anak sungai alamiah serta sistem saluran drainase dan kanal penampung banjir buatan yang ada tidak mampu menampung akumulasi air hujan tersebut sehingga meluap [1][2][3].

Desa Sumengko merupakan salah satu wilayah di Kabupaten Nganjuk yang memiliki luas lahan pertanian yang cukup besar, luasnya mencapai 383,34 Ha. Mata pencaharian utama penduduk di desa Sumengko adalah bercocok tanam atau petani. Dengan demikian kebutuhan air guna irigasi pada desa tersebut sangatlah penting [4][5][6]. Tetapi pada kenyataannya pengelolahan air di desa tersebut masih kurang baik, dimana pada saat musim kemarau tiba terjadi kekeringan, sehingga pasokan air guna irigasi pada desa tersebut kurang memadai untuk mengairi sawah [7]. Namun sebaliknya, pada saat musim penghujan tiba sering kali terjadi banjir akibat luapan kali disekitar wilayah desa tersebut. Luapan air yang cukup besar tersebut mengakibatkan saluran drainase tidak mampu lagi menampung debit air hujan yang terjadi.

\section{METODE PENELITIAN}

\subsection{Lokasi Penelitian.}

Penelitian ini dilakukan di desa Sumengko kecamatan Sukomoro kabupaten Nganjuk.

\subsection{Pendahuluan}

Drainase yang berasal dari bahasa Inggris drainage mempunyai arti mengalirkan, menguras, membuang, atau mengalihkan air [8]. Dalam bidang teknik sipil, secara umum drainase dapat didefinisikan sebagai suatu tindakan untuk mengurangi kelebihan air, yangberasal dari hujan, rembesan, maupun kelebihan air irigasi dari suatu kawasan/ lahan, sehingga fungsi kawasan/ lahan tidak terganggu [9][10]. Drainase juga diartikan sebagai usaha untuk mengontrol kualitas airtanah dalam kaitannya sanitasi. Jadi, menyangkut tidak hanya air permukaan tapi juga air tanah [5][11]. Dari sudut pandang yang lain, drainase adalah salah satu unsur dari perasana umum yang dibutuhkan masyarakat kota dalam rangka menuju kehidupan kota yang aman, nyaman, bersih, dan sehat [12][13]. Kebutuhan terhadap drainase berawal dari kebutuhan air untuk kehidupan manusia di mana untuk kebutuhan tersebut manusia memanfaatkan sungai untuk kebutuhan rumah tangga, pertanian, perikanan, peternakan dan lainnya[14][15]. Drainase merupakan prasarana yang 
berfungsi mengalirkan air permukaan ke badan air dan atau ke drainase bangunan resapan buatan [16].

\subsection{Data Hujan}

Hujan merupakan komponen terpenting dalam analisis hidrologi pada perancangan debit untuk menentukan dimensi saluran drainase [17]. Pengukuran hujan dilakukan selama 24 jam, dengan cara ini berarti hujan diketahui adalah hujan total yang terjadi selama satu hari. Untuk berbagai kepentingan perancangan drainase tertentu data hujan yang diperlukan tidak hanya data hujan harian, akan tetapi juga distribusi jam jaman atau menitan [18].

\subsection{Pengelolaan Data Hujan}

\subsubsection{Rata-Rata Aljabar}

Cara ini adalah perhitungan rata - rata secara aljabar curah hujan di dalam dan di sekitar daerah daerah yang bersangkutan.

$$
R=1 / n(R 1+R 2+\ldots \ldots+R n)
$$

Di mana :

$\mathrm{R}=$ = Curah hujan daerah

$\mathrm{n}=$ = Jumlah titik atau pos pengamatan

$$
\mathrm{R} 1, \mathrm{R} 2, . . \mathrm{Rn}=\text { Curah hujan di tiap titik pengamatan }
$$

\subsubsection{Analisis Probabilitas Frekuensi Debit Bajir}

Tabel 2.1 Persyaratan parameter statistik suatu distribusi.

3.

\begin{tabular}{|l|l|l|}
\hline No & Jenis Distribusi & Persyaratan \\
\hline \multirow{2}{*}{1} & \multirow{2}{*}{2 Metode Gumbel } & $\mathrm{Cs}=1,14$ \\
\cline { 3 - 3 } & & $\mathrm{Ck}=5,4$ \\
\hline \multirow{2}{*}{3} & \multirow{2}{*}{ Metode Normal } & $\mathrm{Cs} \approx 0$ \\
\cline { 3 - 3 } & & $\mathrm{Ck} \approx 3$ \\
\hline 4 & Metode Log Normal & $\mathrm{Cs}=3 \mathrm{Cv}+\mathrm{Cv}^{2}$ \\
\cline { 3 - 4 } & & $\begin{array}{l}\mathrm{C}_{\mathrm{k}}=\mathrm{C}_{\mathrm{v}}{ }^{2}+6 \mathrm{C}_{\mathrm{v}}{ }^{4}+16 \mathrm{C}_{\mathrm{v}}{ }^{2}+ \\
\end{array}$ \\
\hline
\end{tabular}

Keterangan dari Tabel 2.1 
- $\quad$ Koefisien Kepencengan $(\mathrm{Cs})=\frac{\mathrm{n} \sum\left\{(\mathrm{Xi})-\overline{\mathrm{X}}{ }^{3}\right.}{(\mathrm{n}-1)(\mathrm{n}-2) \mathrm{Sd}^{3}}$

- $\quad$ Koefisien Kurtosis $(\mathrm{Ck})=\frac{\frac{1}{\mathrm{n}} \sum_{\mathrm{i}=1}^{\mathrm{n}}\{(\mathrm{Xi})-\overline{\mathrm{X}}\}^{4}}{\mathrm{Sd}^{4}}$

- $\quad$ Standart Deviasi $(\mathrm{Sd})=\sqrt{\frac{\sum\left(\mathrm{Xi}-\overline{\mathrm{X}}^{2}\right.}{\mathrm{n}-1}}$

- $\quad C v=\frac{S d}{\bar{X}}$

- $\mathrm{Xi} \quad=$ data hujan atau debit ke-i

- $\mathrm{n} \quad=$ jumlah data

1. Distribusi Probabilitas Gumbel Tipe I

$$
X T=\bar{X}+S x K
$$

2. Distribusi Probabilitas Normal

$$
X T=\bar{X}+K T S \text {. }
$$

3. Distribusi Log Normal

$$
\log X T=\overline{\log X}+K T x S \log X
$$

4. Distribusi Log Pearson III

$$
\log X T=\overline{\log X}+K T x S \log X
$$

2.3.3 Uji Distribusi Probabilitas Metode Chi-Kuadrat

$$
\chi^{2}=\sum_{i-1}^{n} \frac{(O f-E f)^{2}}{E f} .
$$

2.3.4 Luas (A) dan Koefisien Pengaliran (C)

$$
\mathrm{C}=\frac{(\mathrm{C} 1 \times \mathrm{A} 1)+(\mathrm{C} 2 \times \mathrm{A} 2)+(\mathrm{C} 3 \times \mathrm{A} 3)+\cdots+(\mathrm{Cn} \times \mathrm{An})}{\mathrm{A} 1+\mathrm{A} 2+\mathrm{A} 3+\cdots+\mathrm{An}}
$$

\subsubsection{Debit Banjir Rencana}

Rumus metode rasional adalah untuk menentukan debit banjir rancangan.

Yang dihasilkan hanya debit puncak banjir.

$$
\mathrm{Qr}=\frac{1}{3,6} \mathrm{C} \times \mathrm{I} \times \mathrm{A}
$$

\subsubsection{Intensitas Curah Hujan}

Untuk perhitungan intensitas curah hujan digunakan rumus Mononobe :

$$
\mathrm{I}=\frac{\mathrm{R}_{24}}{24}\left(\frac{24}{\mathrm{tc}}\right) 2 / 3
$$

\subsubsection{Waktu Konsentrasi (tc)}

Waktu konsentrasi dapat dihitung dengan menggunakan rumus sebagai berikut : 


$$
\begin{array}{ll}
\text { tc }=\frac{\mathrm{L}}{\mathrm{V}} & \\
\mathrm{V} & =72 *\left(\frac{\mathrm{H}}{\mathrm{L}}\right) 0,6
\end{array}
$$

\subsection{Aspek Hidrolika}

\subsubsection{Dimensi Penampang Saluran}

Dimensi saluran harus mengalirkan debit rencana atau dengan kata lain debit yang dialirkan oleh saluran (Qs) sama atau lebih besar dari rencana (Qr). Hubungan ini ditunjukkan sebagai berikut:

$$
Q s \geq Q r
$$

Debit suatu penampang saluran (Qs) dapat diperoleh dengan menggunakan rumus seperti di bawah ini :

$$
Q s=A s x V
$$

Rumus Manning sebagai berikut :

$$
V=\frac{1}{n} x R^{2 / 3} x S^{1 / 2}
$$

Berikut adalah rumus mencari dimensi penampang saluran yang didapatkan dari Pd. T-02-2006-B [10] Pedoman Konstruksi dan Bangunan, Perencanaan Sistem Drainase Jalan :

(1) Saluran bentuk trapesium :

$$
\begin{array}{ll}
\text { As } & =(B+m) \times h \\
P=B+2 \times & h \sqrt{1+m^{2}} \\
R \quad=\frac{(B+m) x h}{B+2 \times h \sqrt{1+m^{2}}}
\end{array}
$$

\subsection{Data Teknis}

- Lokasi Penelitian :Jalan Merdeka, Desa Sumengko, Kec.Sukomoro,

$$
\text { - Kab.Nganjuk }
$$

- Jenis Penelitian : : Saluran Drainase

- Waktu Penelitian : Bulan April s/d Juni 2019

- Data yang Diperlukan :Data Curah Hujan, Ukuran Saluran Eksiting Desa Sumengko, Data Teknis Jalan Desa Sumengko, Data Teknis Desa Sumengko, Peta StasiunCurah Hujan, Peta Desa Sumengko, Peta Daerah Rawan Banjir

\subsection{Metode Penelitian}

Metode penelitian yang dipilih menggunakan Metode Penelitian Deskriptif Kuantitatif, Beberapa metode pendukung digunakan dengan menggunakan studi 
literatur atau kepustakaan dengan mengutip dari buku, jurnal, berita dan survei lapangan dengan observasi langsung ke lokasi yang akan dikaji. Sedangkan perhitungan mengikuti ketentuan dari Pd. T-02-2006-B mengenai Perencanaan Sistem Drainase Jalan dan refrensi-refrensi dari penelitian yang relevan.

\section{HASIL DAN PEMBAHASAN}

\subsection{Analisa Hasil Penelitian dan Pembahan}

Analisa penelitian dilakukan dengan mengumpulkan data curah hujan harian dari 3 stasiun pencatat curah hujan terdekat daerah yang akan diteliti. Tiga stasiun tersebut antara lain Sta Pace, Sta Patihan dan Sta Banaran dan data teknis desa Sumengko. Data yang telah didapatkan kemudian akan diolah dengan menggunakan rumus-rumus yang telah dibahas pada Bab dua.

\subsection{Analisa Probabilitas Frekuensi Debit Banjir}

Berikut ini adalah data rekapitulasi dari pengelolahan data curah hujan harian dari 3 stasiun yang ada dengan menggunakan beberapa metode jenis sebaran, yaitu Metode Gumbel Tipe I, Metode Normal, Metode Log Normal, dan Metode Log Person III.

Tabel 2. Data rekapitulasi pengolahan data curah hujan harian

\begin{tabular}{|l|l|l|l|l|l|}
\hline No & Periode & $\begin{array}{l}\text { Metode } \\
\text { Gumbel }\end{array}$ & $\begin{array}{l}\text { Metode } \\
\text { Normal }\end{array}$ & $\begin{array}{l}\text { Metode Log } \\
\text { Normal }\end{array}$ & $\begin{array}{l}\text { Metode Log } \\
\text { Person III }\end{array}$ \\
\hline 1 & 2 & 93,153 & 94,933 & 94,125 & 95,416 \\
\hline 2 & 5 & 108,862 & 105,992 & 105,659 & 105,906 \\
\hline 3 & 10 & 119,266 & 111,784 & 112,254 & 111,025 \\
\hline 4 & 20 & 129,245 & 116,523 & 117,955 & 116,151 \\
\hline 5 & 50 & 142,161 & 121,921 & 124,802 & 119,261 \\
\hline 6 & 100 & 151,840 & 125,607 & 129,705 & 121,916 \\
\hline 7 & 200 & - & - & 134,244 & 124,219 \\
\hline
\end{tabular}

Sumber : Perhitungan

\subsection{Analisa Hidrolika}

Analisa hidrolika bertujuan untuk mengetahui kemampuan penampang saluran drainase sepanjang $2.300 \mathrm{~m}$ dalam menampung debit limpasan yang terjadi.

\subsubsection{Perhitungan Kecepatan Aliran (V)}

Rumus untuk menghitung kecepatan aliran dalam saluran menggunakan rumus manning yaitu sebagai berikut : 


$$
V=\frac{1}{n} R^{2 / 3} S^{1 / 2}
$$

Untuk memperoleh nilai Radius Hidroulik (R) dibutuhkan nilai luas penampang dan keliling basah. Luas penampang (A) menggunakan rumus sebagai berikut :

$$
\text { As }=\mathrm{B} \times \mathrm{h}=0,30 \times 0,35=0,105 \mathrm{~m} 2
$$

Keliling basah $(\mathrm{P})$ didapat dengan rumus sebagai berikut :

$\mathrm{P}=\mathrm{B}+2 \mathrm{~h}=0,30+2 \cdot(0,35)=1,00 \mathrm{~m}$

Dapat dihitung nilai rumus radius hidroulik $(\mathrm{R})$ sebesar :

$\mathrm{R}=\frac{\mathrm{As}}{\mathrm{P}}=\frac{0,105}{1}=0,105 \mathrm{~m}$

Untuk kemiringan dasar saluran didapat dengan rumus sebagai berikut:

$$
\mathrm{S}=\frac{\Delta \mathrm{H}}{\mathrm{L}} \times 100 \%=\frac{0.07}{7} \times 100 \%=0,01
$$

Maka, kecepatan aliran (V) untuk saluran drainase, dapat dihitung sebagai berikut :

$$
\begin{aligned}
\mathrm{V} & =\frac{1}{\mathrm{n}} \cdot \mathrm{R}^{2 / 3} \cdot \mathrm{S}^{1 / 2}=\frac{1}{0,020} \cdot 0,1052 / 3 \cdot 0,011 / 2 \\
& =1,10 \mathrm{~m} / \mathrm{det}
\end{aligned}
$$

Kecepatan aliran (V) dari hasil perhitungan didapatkan 1,10 m/detik. Sementara, kecepatan aliran yang diizinkan bagi jenis bahan beton adalah $1,5 \mathrm{~m} /$ detik. Artinya kecepatan aliran (V) sebesar $1,10 \mathrm{~m} /$ detik bisa dipakai.

\subsubsection{Perhitungan Daya Tampung Debit Saluran (Qs)}

Perhitungan daya tampung debit saluran dapat dihitung dengan rumus sebagai berikut :

$\mathrm{Qs}=\mathrm{As} \times \mathrm{V}=0,105 \times 1,10=0,12 \mathrm{~m} 3 / \mathrm{det}$

Dari hasil perhitungan diatas didapatkan nilai daya tampung debit saluran (Qs) sebesar 0,12 m3/det. Sedangkan nilai debit banjir rencana (Qr) yang terjadi sebesar 0,41 m3/det, Qs $<$ Qr. Ini membuktikan bahwa saluran drainase yang sudah ada (Eksisting) tidak dapat menampung debit limpasan yang terjadi. Untuk itu perlu adanya redimensi terhadap saluran drainase eksisting.

\subsection{Perencanaan Ulang Dimensi Saluran Drainase}

Perencaan adalah proses mencoba meletakkan dasar tujuan dan sasaran termasuk menyiapkan segala sumber daya untuk mencapainya. Perencanaan menempati urutan pertama dari fungsi - fungsi lain seperti mengorganisir, memimpin, dan mengendalikan [20].

\subsubsection{Analisa Redimensi Saluran Drainase}

Bentuk penampang saluran drainase baru yang akan direncanakan ulang adalah trapesium. Berikut adalah data yang diperlukan dalam redimensi saluran drainase :

$\begin{array}{lll}\text { Debit Rencana } & : \text { Qr } & =0,41 \mathrm{~m}^{3} / \text { detik } \\ \text { Kemiringan tebing } & : \mathrm{m} & =1: 1 \\ \text { Kemiringan dasar } & : \mathrm{S} & =0,01\end{array}$


Koef.Kekasaran manning $: \mathrm{n} \quad=0,020$ (angka Kekasaran Manning)

Lebar Saluran drainase $\quad: \mathrm{b} \quad=0,40 \mathrm{~m}$ (direncanakan)

Perencanaan :

1) Menghitung luas penampang saluran (A) untuk saluran berbentuk Trapesium:

$$
\begin{aligned}
\text { A } & =\frac{0,4+0,4+h+h}{2} \times h \\
& =0,4 \mathrm{~h}+\mathrm{h} 2
\end{aligned}
$$

2) Menghitung keliling basah (P) untuk saluran berbentuk Trapesium :

$$
\begin{aligned}
\mathrm{P} & =\mathrm{h} \sqrt{2}+0,4+\mathrm{h} \sqrt{2} \\
& =2,82 \mathrm{~h}+0,4
\end{aligned}
$$

3) Menghitung jari-jari hidraulis (R) :

$\mathrm{R}=\frac{\mathrm{A}}{\mathrm{P}}=\frac{0,4 \mathrm{~h}+\mathrm{h}^{2}}{2,82 \mathrm{~h}+0,4}$

4) Menghitung Debit saluran drainase :

$$
\begin{aligned}
\text { Qs } & =V \cdot A \quad=\frac{1}{n} \cdot R^{2 / 3} \cdot S^{1 / 2} \cdot A \\
& =\frac{1}{0,020} \cdot \frac{0,4 h+h^{2}}{2,82 h+0,4} \cdot 0,011 / 2 \cdot 0,4 h+h 2
\end{aligned}
$$

Merencanakan kedalaman saluran yang tergenang air (h) dengan mempertimbangkan persyarat $(\mathrm{Qs} \geq \mathrm{Qr})$

$$
\mathrm{h}=0,25 \mathrm{~m}
$$

Qs $\quad \geq \quad$ Qr

$\frac{1}{0,020} \cdot \frac{0,4(0,25)+(0,25)^{2}}{2,82(0,25)+0,4} \cdot 0,011 / 2 \cdot 0,4(0,25)+(0,25) 2 \geq 0,4 \mathrm{~m} 3 / \mathrm{det}$

$0,23 \mathrm{~m} 3 / \mathrm{det} \geq 0,41 \mathrm{~m} 3 / \mathrm{det} \quad$ (Tidak Ok)

$\mathrm{h}=0,30 \mathrm{~m}$

$$
\begin{aligned}
& \text { Qs } \geq \quad \text { Qr } \\
& \frac{1}{0,020} \cdot \frac{0,4(0,30)+(0,30)^{2}}{2,82(0,30)+0,4} \cdot 0,011 / 2 \cdot 0,4(0,30)+(0,30) 2 \geq 0,4 \mathrm{~m} 3 / \text { det } \\
& 0,32 \mathrm{~m} 3 / \text { det } \geq 0,41 \mathrm{~m} 3 / \text { det } \quad \text { (Tidak Ok) } \\
& \mathrm{h}=0,35 \mathrm{~m}
\end{aligned}
$$

$$
\begin{aligned}
& \text { Qs } \quad \geq \quad \text { Qr } \\
& \frac{1}{0,020} \cdot \frac{0,4(0,35)+(0,35)^{2}}{2,82(0,35)+0,4} \cdot 0,011 / 2 \cdot 0,4(0,35)+(0,35) 2 \geq 0,4 \mathrm{~m} 3 / \text { det } \\
& 0,43 \mathrm{~m} 3 / \text { det } \geq 0,41 \mathrm{~m} 3 / \text { det } \quad(\mathrm{Ok})
\end{aligned}
$$

Hasil dari analisa redimensi saluran drainase yang direncanakan dengan bentuk trapesium dan memenuhi syarat perbandingan kapasitas daya tampung debit saluran (Qs) lebih besar atau sama dengan debit banjir rencana (Qr), Qs $\geq$ Qr yaitu sebagai berikut : 
Lebar bawah saluran (b) $=0,40 \mathrm{~m}$

Kedalaman saluran yang tergenang air $(\mathrm{h})=0,35 \mathrm{~m}$

Tinggi jagaan $(w)$ $=0,20 \mathrm{~m}$

\section{KESIMPULAN}

Berdasarkan hasil perhitungan analisa sistem jaringan drainase di lingkungan Desa Sumengko, Kecamatan Sukomoro, Kabupaten Nganjuk, maka didapat beberapa kesimpulan yang diuraikan sebagai berikut :

1. Desa Sumengko merupakan daerah dengan intensitas curah hujan (I) yang cukup tinggi yaitu mencapai $29,40 \mathrm{~mm} / \mathrm{jam}$.

2. Debit banjir rencana untuk periode ulang 10 tahunan didapat sebesar $0,41 \mathrm{~m} 3 /$ detik.

3. Kapasitas daya tampung saluran drainase yang ada pada kawasan Jalan Merdeka, desa Sumengko sepanjang 2,3 km sebesar 0,12 m3/detik. Sedangkan debit banjir rencana (Qr) sebesar 0,41 m3/detik. Hal ini membuktikan bahwa kondisi saluran drainase eksisting yang buruk dalam menampung debit air hujan yang terjadi.

4. Salah satu permasalahan akibat ketidakmampuan saluran drainase dalam menampung debit limpasan yang terjadi adalah ukuran penampang. Ukuran yang kurang memadai untuk menampung debit banjir rencana (Qr) menyebabkan kawasan jalan Merdeka, desa Sumengko rawan akan banjir. Untuk mengatasi permasalahan tersebut, perlu adanya redimensi saluran agar mampu menampung debit limpasan yang terjadi ketika musim hujan. Perencanaan dimensi penampang saluran dibuat dengan menganalisa perbandingan Qs dan Qr. Syarat perbandingan yang memenuhi ialah Qs $\geq$ Qr. Dari analisa dimensi saluran drainase yang dilakukan, menghasilkan saluran baru bentuk trapesium dengan lebar bawah saluran (b) : 0,40 m; kedalaman saluran yang tergenang air (h) : 0,35 $\mathrm{m}$; dan tinggi jagaan $(\mathrm{w}): 0,20 \mathrm{~m}$.

\section{SARAN}

Berdasarkan hasil analisis sistem jaringan drainase di lingkungan Desa Sumengko, Kecamatan Sukomoro, Kabupaten Nganjuk, maka dapat disarankan sebagai berikut : Melakukan pelebaran dimensi pada saluran drainase di Desa Sumengko. Melakukan normalisasi pada saluran drainase di Desa Sumengko dengan cara mengeruk endapan, sedimen, dan sampah yang menumpuk secara berkala setiap bulan. Memberikan himbauan kepada masyarakat sekitar untuk tidak membangun bangunan permanen yang menutup saluran drainase di lingkungan Desa Sumengko. 


\section{UCAPAN TERIMAKASIH}

Dalam penyusunan artikel ini, penulis ucapkan terimakasih kepada dosen pembimbing dan Universitas Kadiri. Penulis berharap agar artikel ini dapat bermanfaat bagi pembaca.

\section{DAFTAR PUSTAKA}

[1] Badan Koordinasi Nasional Penanggunangan Bencana [BAKORNAS PB], "Pedoman Penanggulangan Bencana Banjir," Bakornas Pb, 2007.

[2] A. Rahmawati, A. Damayanti, and E. S. Soedjono, "Evaluasi Sistem Drainase Terhadap Penanggulangan Genangan di Kota Sidoarjo," Atpw, no. October, pp. 1-8, 2015.

[3] A. Nashirudin, S. Winarto, and Sudjati, "PERENCANAAN CHECKDAM KALI NGASINAN KANAN DESA NOTOREJO KECAMATAN GONDANG KABUPATEN TULUNGAGUNG,” Jurmateks, vol. 1, no. 2, pp. 192-203, 2018.

[4] O. A. Swenda, A. Ridwan, and S. Winarto, "ANALISA KEBUTUHAN AIR BAKU BERDASARKAN MATA AIR SUNGAI BAYONG ( Study Kasus di Kec. Bendungan Kab. Trenggalek )," Jurmateks, vol. 2, no. 1, pp. 51-64, 2019.

[5] Suripin, Sistem Drainase Perkotaan Yang Berkelanjutan. Yogyakarta : Andi Offset, 2006.

[6] R. D. Prasetyo, Y. Cahyo, and A. Ridwan, "ANALISA PERENCANAAN SISTEM DRAINASE DALAM UPAYA PENANGGULANGAN BANJIR DI KECAMATAN GANDUSARI KABUPATEN TRENGGALEK," Jurmateks, vol. 2, no. 1, pp. 132-143, 2019.

[7] A. I. Candra, "ANALISIS DAYA DUKUNG PONDASI STROUS PILE PADA PEMBANGUNAN GEDUNG MINI HOSPITAL UNIVERSITAS KADIRI,” Ukarst, vol. 1, no. 1, pp. 63-70, 2017.

[8] R. Tamimi, S. Wahyuni, and E. Hidayah, "Kajian Evaluasi Sistem Drainase Jalan Srikoyo Kecamatan Petrang Kabupaten Jember,” Rekayasa Sipil, vol. 10, no. 2, pp. 106-113, 2016.

[9] DEPARTEMEN PEKERJAAN UMUM [PUCIPTAKARYA], "Buku Panduan Sistem Drainase Mandiri Berbasis Masyarakat yang Berwawasan Lingkungan.”

[10] DEPARTEMEN PEKERJAAN UMUM, "Perencanaan Sistem Drainase Jalan,” 2006.

[11] A. A. Rofiq, L. D. Krisnawati, and S. Winarto, "KAJIAN KEBUTUHAN AIR BERSIH PDAM NGANCAR KABUPATEN KEDIRI,” Jurmateks, vol. 1, no. 1, pp. 126-136, 2018.

[12] A. I. Candra, "ANALISIS DAYA DUKUNG PONDASI STROUS PILE PADA PEMBANGUNAN GEDUNG MINI HOSPITAL UNIVERSITAS KADIRI Agata," Ukarst, vol. 1, no. 1, pp. 63-70, 2017.

[13] E. Supriyani, M. Bisri, and V. Dermawan, "STUDI PENGEMBANGAN SISTEM 
DRAINASE PERKOTAAN BERWAWASAN LINGKUNGAN,” vol. 3, pp. 112-121, 2012.

[14] Wesli, Drainase Perkotaan. Yogyakarta : Graha Ilmu, 2008.

[15] F. Isnaini, Y. Sri Sundari, and H. Purnomo, "Evaluasi Kapasitas Daya Tampung Saluran Drainase Jalan Damanhuri Pada Kota Samarinda," J. Chem. Inf. Model., vol. 53, no. 9, pp. 1689-1699, 2013, doi: 10.1017/CBO9781107415324.004.

[16] H.R. Mulyanto, Penataan Drainase Perkotaan, Cetakan Pe. Yogyakarta ; Graha Ilmu, 2013.

[17] H. . H. Hasmar, Drainasi Terapan. Yogyakarta : UII Press, 2011, 2011.

[18] R. S. Robert J. Kodoatie, Tata Ruang Air. Penerbit Andi, 2010.

[19] I. M. Kamiana, Teknik Perhitungan Debit Rencana Bangunan Air, Edisi pert. Yogyakarta : Graha Ilmu, 2016.

[20] I. I. Soeharto, MANAJEMEN PROYEK Dari Konseptual sampai Operasional. Jakarta: Erlangga, 1997. 